\title{
Pertussis infection in adolescents and adults with persistent cough: A Review
}

\author{
Kazi Yesmin \\ Department of Microbiology, Green Life Medical College
}

\begin{abstract}
Pertussis or whooping cough, generally considered as the disease of infants and children, is an acute respiratory tract disease responsible for around 300,000 deaths annually. However, recent reports from many countries of the world clearly indicate that people of all age groups including adolescent and adults could be suffering from this disease. Pertussis remains an underestimated and under reported disease in adolescent and adults due to atypical symptoms in these age groups. Moreover, pertussis has been re-discovered as a frequent cause of prolonged cough in adolescents and adults in the recent past but the diagnosis still is often missed unless specific diagnostic tests are applied. The affected adolescents and adults act as reservoirs of the disease to the vulnerable population of infants. There have been increasing reports of pertussis outbreaks in adults' population in many western countries and vaccination of this group is being planned. Additional booster doses of acellular pertussis vaccine may help to control and prevent pertussis.
\end{abstract}

Key Word: Pertussis

\section{Introduction}

Cough is a major reason for contact with general practitioners, accounting for nearly 30 million visits a year to primary care physicians in the United States ${ }^{1}$. Cough may be caused by several factors including microorganisms. $B$. pertussis and $B$. parapertussis cause whooping cough in human which is one of the major health problems in the world and transmitted person to person by close contact with aerosolized droplets ${ }^{2}$. Whooping cough is still a major disease worldwide and one of the important cause of death in malnourished children. It is estimated that there were over $51,000,000$ cases of pertussis each year worldwide and 600,000 were reported deaths ${ }^{3}$. In most populations the disease is endemic, with epidemics occurring every 4 years in late winter and spring ${ }^{4}$. It is a widely held belief that pertussis is an exclusive childhood disease while in reality it affects all age groups ${ }^{5}$.

\section{Correspondence:}

Dr. Kazi Yesmin

Assistant Professor

Department of Microbiology

Green Life Medical College, Green Road, Dhaka.

E-mail : evaadiba@gmail.com
Wide-spread immunization among children has controlled the disease successfully since its introduction in the early 1940s for several decades ${ }^{6}$. Adults with waning vaccine-induced immunity are increasing and also suffering from pertussis ${ }^{7}$. Recently, an increase in reported cases of pertussis in adolescents and adults has been noted quite increasing in number in many countries despite of high immunization rates in children ${ }^{8}$. The clinical presentation in adolescents, adults and vaccinated individuals may be atypical, with paroxysmal cough of short duration or simply a persistent cough ${ }^{9-10}$. It has been suggested that up to $30 \%$ of adults with a prolonged cough may be due to from pertussis ${ }^{11}$. Approximately 13$20 \%$ have cough illnesses in adolescents and adults were due to $B$. pertussis infection ${ }^{12}$. The majority of the cases which were diagnosed clinically as bronchitis or upper respiratory infection bt these cold be a case of pertussis which would remain unrecognized ${ }^{13}$.

A study in China on multicentral clinical investigations of pertussis in children and adolescents with persistent cough found that about $11.3 \%$ patients were $B$. pertussis positive who had cough for more than 2 weeks ${ }^{14}$. In a study in Denmarks it was found that the prevalence rate among association of $B$. pertussis with adults patients having chronic 
cough for $2-12$ weeks, about $2 \%$ were found $B$. pertussis culture positive, $5.47 \%$ were $B$. pertussis $\mathrm{PCR}$ positive and $16.42 \%$ were positive for antibody for pertussis toxin ${ }^{15}$. In the United States, Wright (1995) carried out a study on pertussis infection in adults with persistent cough and demonstrated that no subject was culture positive for $B$. pertussis, but $21 \%$ subjects met the serological criteria for pertussis infection ${ }^{16}$. To evaluate the pertussis infection in Canada among adolescents and adults who had cough related illness of 7- 56 days durations were found that $19.9 \%$ had either laboratory - confirmed pertussis or laboratory evidence of pertussis ${ }^{17}$. In both Canada and the United States, Guris et al reported the highest incidence of pertussis cases among infants; as well as the rapid increase in incidence among adolescents and adults ${ }^{18}$. Pertussis has been shown to be an important cause of cough illness in college students, military recruits, referrals to pulmonary specialist and visitors to hospital emergency departments ${ }^{19-21}$. In India, about $9.52 \%$ patients found were culture positive for B. pertussis and $14.28 \%$ patient found were positive by direct florescence antibody (DFA) among patients having cough for more than 2 weeks ${ }^{22}$. Study on German adults who received pertussis subsequently suffering from cough illness that lasted more than 1 week had shown $26 \%$ prevalence in favor of laboratory evidence of pertussis ${ }^{23}$. Seroepidemiological studies suggest that pertussis is a common and frequently unrecognized infection in adults ${ }^{24-27}$. A US study of adults with cough illness of more than 2 weeks duration found a prevalence of $B$. pertussis is $12.4 \%$; where, only a single serum sample as tested, only IgG antibodies to pertussis toxin ${ }^{28}$. Cherry studied on prolonged cough illness in adolescents and adults and reported that between 12 to $32 \%$ were due to the $B$. pertussis infection ${ }^{29-32}$.

There have been increasing reports of pertussis out breaks in adult's population in many western countries and vaccination of this group is being planned ${ }^{33}$. Like many other developing countries of the world, morbidity and mortality rate due to pertussis is likely to be high in South Asian countries such as Pakistan, India, Bangladesh and Sri Lanka as well as countries of African continent ${ }^{34-36}$. There is also a very high probability of occurrence of adult's pertussis case in this region. Furthermore there is an overall lack of data related to laboratory confirmed cases of pertussis from these regions. The main reason behind this under reporting may be due to lack of adequate diagnostic facilities, poor surveillance systems and unawareness of physicians to the occurrence of these infections in adult population. Widespread use of DPT vaccination has resulted in the shifting of incidence of pertussis to adolescents and adults ${ }^{37}$. It is estimated that almost $20-50 \%$ of all persistent cough cases in adults are caused by the $B$. pertussis ${ }^{38-39}$. Adult pertussis is both a significant health problem as well as an economic burden in both developing as well as developed countries ${ }^{40}$.

In recent years there has been much concern in the lay and scientific literature about the "resurgence of pertussis" ${ }^{41}$.To summarize, there are 5 possible causes for the increased reporting of pertussis: (1) genetic changes in $B$. pertussis making vaccines less effective; (2) lessened potency of pertussis vaccines; (3) waning of vaccine-induced immunity; (4) greater awareness of pertussis and (5) the general availability of better laboratory tests in some areas of the country 42 .

Active immunization is the primary method of preventing pertussis. Control of pertussis requires continuous use of whole-cell or acellular pertussis vaccines to achieve and maintain pediatric vaccine coverage levels in excess of $90 \%$ and consider to adding booster doses during adulthood to prevent disease in that segment of the population and its subsequent transmission to infant ${ }^{43}$. Acellular vaccines are currently licensed and being used in the UK, USA, Japan, Germany and Italy. They appear to be safe and effective and may soon replace whole-cell vaccines ${ }^{44}$. The immunity on account of pertussis vaccine is estimated to last for about 3-5 years ${ }^{45-46}$.

In spite of good immunization coverage, the developed countries have shown a shift in the epidemiology of the disease to the adolescent and the adult age group, leading to a revision of their vaccination policies ${ }^{47}$. The anticipation and early recognition of this change in the epidemiology is important because the affected adolescents and adults act as reservoirs of the disease to the vulnerable population of infants, for whom the disease can be life threatening ${ }^{48}$.

Research in several countries had shown that pertussis is endemic among the adolescents and adults. It is suggested that a universal program of adolescent and adult boosters would decrease the circulation of B. pertussis in these age groups and possibly could lead to the elimination of the organism from the population ${ }^{49}$. With the availability of vaccine, booster doses in adolescents have been introduced in Canada, Austria, Australia, France, Germany and the US, and many other countries are considering similar expansion of their immunization programms at present. In addition, universal immunization of adults (Austria, every 10 years) or targeting high groups (e.g., parents of newborns and other care-giver to children; Germany) are being practiced $^{47,50}$. 


\section{Conclusion}

Although the immunization rate of DPT is high, B. pertussis is still an important etiological factor associated with persistent cough. Pertussis is a common cause of persistent cough in adults and should be considered in differential diagnosis. Booster doses of acellular pertussis vaccine for children aged 6-8 years and adolescent or young adults aged 15-20 years may help to control and prevent pertussis.

\section{Reference}

1. Braman SS, Corraow M. Chronic cough: diagnosis and treatment. Prim Care 1985; 12: 217- 225.

2. Viljanen MK, He Q, Arvilommi H, Aittanen B, Mertsola J. Whooping cough caused by B. pertussis and B. parapertussis in an immunized population. JAMA, 1998; 280: 635-637.

3. Ryan KJ, Ray CG. Haemophilus \& Bordetella. In: Ryan KJ, Ray CG, editors. Sherris Medical Microbiology, 4th edition, New York: McGrew Hill; 2004: pp.401-407.

4. Winter K, Harriman K, Zipprich J. California pertussis epidemic, 2010. J Pediatr 2012; 129: 968-970.

5. Aoyama T, Takeuchi Y, Goto A, Iwai H, Murase Y, Iwata T et al. Pertussis in adults. Am J Dis Child 1992; 146: 163-6.

6. Marchant CD, Loughlin AM, Lett SM. Pertussis in Massachsetts, 1981-1991: incidence serologic diagnosis, and vaccine effectiveness. J Infect Dis 1994; 169: 1297305.

7. Slack MPE. Gram Negative Coccobacilli. In: Cohen J, Powderly WG editors. Infectious Diseases, 2nd edition. USA: Mosby Inc; 2004:pp.401-404.

8. Heininger U. Pertussis immunization in adolescents and adults. Springerlink, New York, 2008; 609: 72-97.

9. Heininger U, Cherry JD, Expert opinion on biological therapy, 2006; 6: 685-697.

10. Singh M, Lingappan K. Pertussis infection in adults with persistent cough. JAMA, 1995; 273: 1044-1046.

11. Strebel P, Nordin J, Edwards K. Population-based incidence of pertussis among adolescents and adults, Minnesota, 1995-1996. J Infect Dis, 2001; 183: 1353 -1359 .

12. Cherry JD. Epidemiological, clinical, and laboratory aspects of pertussis in adults. Clin Infect Dis, 1999; 28:112 -117 .

13. Mink CAM, Cherry JD, Christensen P. A search for Bordetella pertussis infection in university student. Clin Infect Dis, 1992; 14: 464-467.

14. Lin L, Poh KL, Lim TK. Multicenter clinical investigation of pertussis in children and adolescents with persistent cough. Zhonghua Er Ke Za Zhi. 2010; 48 (10): $748-752$.

15. Birkebaek NH, Kristiansen M, Seefedt T, Degn J, Moller A, Heron I et al. B. pertussis and chronic cough in adults. Clin Infect Dis, 1999; 29 (5): 1239 - 42.

16. Wright SW, Edwards KM, Decker MD, Zeldin $\mathrm{MH}$. Pertussis Infection in adults with persistent cough. JAMA, 1995; 273: 1044-1046.

17. Linda DS, Scott AH, John SS, Merrilyn A, Annette M, Bruce $\mathrm{S}$ et al. Pertussis is a frequent cause of prolonged cough in adults and adolescents. Clin Infect Dis, 2001; 32 (12): 1691- 1697.

18. Guris D, Strehel PM, Bardenheier R. Changina epidemiology of pertussis in the United State: increasing reported incidence among adolescent and adults, 19901996. Clin Infect Dis, 1999; 28: 1230-7.

19. Jansen DI, Gray GC, Putnam SD, Iynn E, Meade RD. Evaluation of pertussis in U.S. Marine Corps trainees. Clin Infect Dis, 1997; 25: 1099 - 107.

20. Wright SW, Edwards KM, Decker MD. Incidence of pertussis infection in healthcare workers. Infect Control Hosp Epidemiol 1999; 20: 120 - 3.

21. Rohertson PW, Goldhera H, Laryie RH, Smith DD, Whyhin IR. Bordetella pertussis infection: a cause of persistent cough in adults. Med J Aust 1987; 146: 522 5.

22. Dahiya S, Kapil A, Kabra SK, Mathur P, Sood S, Lodha R et al. Pertussis in India. J Med Microbiol 2009; 58 (5): $688-689$.

23. Schmitt-Grohé S, Cherry JD, Heininger U, Überall MA, Pineda E, Stehr K. Pertussis in German adults. Clin Infect Dis, 1995; 21: 860-866.

24. Cromer BA, Goydos J, Hackell J, Mezzatesta J, Dekker C, Mortimer EA. Unrecognized pertussis infection in adolescents. Am J Dis Child, 1993; 147: 575 -577. 
25. Devile IG, Cherry ID, Christenson PD. Frequency of unrecognized Bordetella pertussis infections in adults. Clin Infect Dis, 1995; 21: 639 -642.

26. Rota MC, Asiello CM, D’Amelio R. Prevalence of markers of exposure to Bordetella pertussis among Italian young adults. Clin Infect Dis, 1998; 26: 297- 302.

27. Cattaneo IA, Reed GW, Haasa DH, Wills MI, Edwards KM. The seroepidemiology of Bordetella pertussis infections: a stdy of persons ages $1-65$ years. J Infect Dis 1996; 173: 1256- 59.

28. Rosenthal S, Strebel P, Cassiday P, Sanden G, Brusuelas $\mathrm{K}$, Wharton $\mathrm{M}$. Pertussis infection among adults during the 1993 outbreak in Chicago. J Infect Dis, 1995; 171: $1650-1652$.

29. Cherry JD. Epidemiological, clinical, and laboratory aspects of pertussis in adults. Clin Infect Dis, 1998; 28 : $112-7$.

30. Nennig ME, Shinefield HR, Edwards KM, Black SB, Fireman BH. Prevalence and incidence of adults pertussis in urban population. JAMA, 1996; 275: 1672-1674.

31. Birkebaek NH, Kristiansen M, Seefeldt T. Bordetella pertussis and chronic cough in adults. Clin Infect Dis, 1999; 29: $1239-1242$.

Gilberg S, Njamkepo E, Du Chatelet IP. Evidence of Bordetella pertussis infection in adults presenting with persistent cough in a French area with very high wholecell vaccine coverage. J Infect Dis, 2002; 186: $415-418$.

33. Bassinet L, Matrat M, Njamkepo E, Aberrane S, Housset B, Guiso N. Nosocromial pertussis out breaks among adults patients and healthcare workers. Infect Control Hosp Epidemiol 2004; 25: 995- 997.

34. Zaidi AKM, Avasthi S, De Silva HJ. Burden of infectious diseases in South Asia. Brit Med J 2004; 328: 811- 815.

35. Shears P. Emerging and reemerging infections in Africa: the need for improved laboratory services and disease surveillance. Microb Infect 2000; 2: 589- 595.

36. World Health Organization. Global Burden of Diseases 2004.

37. Bamberger ES, Srugo I. What is new in pertussis. Eur J Pediatr 2007; 167: 133- 136.

38. Cherry JD. The epidemiology of pertussis: A comparison of the epidemiology of the disease pertussis with the epidemiology of Bordetella pertussis infection. Pediatrics 2005; 115: 1222- 1227.

39. Hoey J. Pertussis in adults. Can Med Assoc J 2003; 168: 453- 454.

40. Weir E. Resurgence of Bordetella pertussis infections. Can Med Assoc J 2002; 167: 1146.

41. Cherry JD. The science and fiction of the "resurgence" of pertussis. Pediatrics. 2003; 112: 405-406.

42. Halperin SA, Wang EEL, Law B. Epidemiological features of pertussis in hospitalized patients in Canada, 1991-1997: report of the Immunization Monitoring Program-Active (IMPACT). Clin Infect Dis, 1999; 28: 1238-1243.

43. Hewlett EL, Halperin SA. Serological correlates of immunity to B. pertussis. Vaccine, 1998; 16: 1899-1900.

44. Campins MM, Cheng HK. Recommendations are needed for adolescent and adults pertussis immunization: rational and strategies for consideration. Vaccine, 2001; 20: 641646.

45. McIntyre PB, Burgess MA, Egan A, Schuerman L, Hoet B. Booster vaccination of adults with reduced-antigencontent diphtheria, Tetanus and pertussis vaccine: Immunogenicity 5 years post-vaccination. Vaccine 2009; 27(7): 1062-6.

46. Elomaa A, He Q, Minh NNT, Mertsola J. Pertussis before and after the introduction of acellular pertussis vaccines in Finland. Vaccine 2009; 27(40):5443-9.

47. Bisgard L. Children with pertussis inform the investigation of other pertussis cases among contacts. JAMA, 2004; 7: 21.

48. Cherry JD. From the Department of Pediatrics, David Geffen School of Medicine, Univer sity of California, Los Angeles, California, 2005: 755-756.

49. Rosenthal S, Strebel P, Cassiday P, Sanden G, Brusuelas $\mathrm{K}$, Wharton $\mathrm{M}$. Pertussis infection among adults during the 1993 outbreak in Chicago. J Infect Dis, 1995; 171 :1650-1652.

50. Mink CAM, Cherry JD, Christensen P. A search for Bordetella pertussis infection in university student. Clin Infect Dis, 1992; 14: 464-467. 